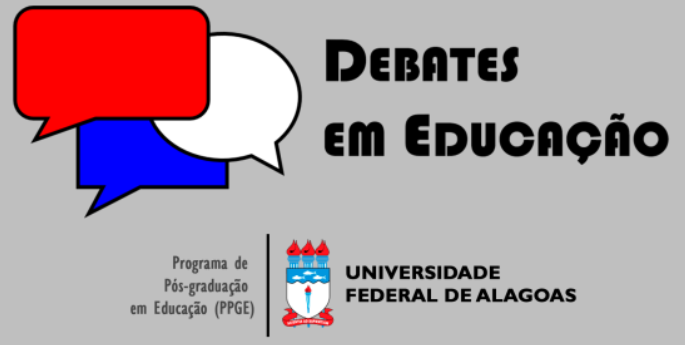

ISSN Eletrônico 2175-6600

Vol. 12 | N. 28 | Set./Dez. | 2020

\section{Camila Santana}

9 i

Instituto Federal de Educação, Ciência e Tecnologia Baiano (IF Baiano)

camilalimasantana@gmail.com

\section{PEDAGOGIA DO (IM)PREVISÍVEL: PANDEMIA, DISTANCIAMENTO E PRESENCIALIDADE NA EDUCAÇÃO}

RESUMO

A pandemia da COVID-19 provocou o fechamento de comércios, fronteiras e escolas em razão das medidas de contenção instituídas por governos. As medidas, no entanto, são mais físicas do que sociais. Em todo mundo, as pessoas migraram suas interações para os ambientes online, forjando outras apropriações e usabilidades. No campo da educação, os desafios que a área já enfrentava diante das transformações da sociedade contemporânea, ganharam novos contornos impostos pelo contexto pandêmico. $\bigcirc$ estudo, realizado por meio de pesquisa bibliográfica e análise de documentos produzidos em função da pandemia, objetiva discutir as noções de presencialidade e distanciamento social na interface com a educação, refletindo sobre os desafios apresentados frente à pandemia e conclui que a crise potencializada pelo coronavírus é também uma oportunidade de assumir as potencialidades de transformação de uma educação inspirada pela pedagogia da presença e articulada com princípios e fundamentos da cibercultura.

Palavras-chave: Educação. Tecnologias Educacionais. Pandemia. Distanciamento Social. Pedagogia da Presença.

\section{PEDAGOGY OF (UN)PREDICTABLE: PANDEMIC, DISTANCING AND PRESENTIALITY IN EDUCATION}

\footnotetext{
ABSTRACT

The COVID- 19 pandemic caused the closure of shops, borders and schools due to the containment measures instituted by governments. The measures, however, are more physical than social. Around the world, people have migrated their interactions to online environments, forging other appropriations and usability. In the field of education, the challenges that the area already faced in the face of the transformations of contemporary society, gained new contours imposed by the pandemic context. The study, carried out through bibliographic research and analysis of documents produced according to the pandemic, aims to discuss the notions of presence and social distance in the interface with education, reflecting on the challenges presented in the face of the pandemic and concludes that the crisis made possible by the corona virus is also an opportunity to assume the potential for transforming an education inspired by the pedagogy of presence and articulated with principles and foundations of cyberculture.
}

Keywords: Education. Educational Technology. Pandemic. Social Distancing. Pedagogy of Presence.

Submetido em: 23/05/2020

Aceito em: 09/07/2020

Publicado em: | 8/08/2020

do http://dx.doi.org// 0.28998/2 I 75-6600.2020v I 2n28p42-62 


\section{CONSIDERAÇÕES INICIAIS}

No momento em que esse texto é escrito, existem confirmados e notificados mais de quatro milhões e setecentos mil ${ }^{1}$ casos de COVID-19, a doença provocada pelo novo coronavírus - SARS-CoV2, no mundo. O número de mortes ultrapassa trezentas mil pessoas, sendo mais de dezessete mil apenas no Brasil. Quase metade da população mundial está em isolamento ou distanciamento e, segundo dados da Unesco², mais de 70\% da população estudantil está com aulas suspensas.

Nesse sentido, certamente, a afirmação que mais se tem lido e ouvido nos últimos meses é a de que a sociedade contemporânea está vivendo, no primeiro semestre de 2020, uma crise sem precedentes. $O$ ineditismo se configura porque a pandemia causada pela COVID-19 engendrou desequilíbrio em muitas áreas, simultaneamente, em um mundo globalizado. De repente, o mundo precisou parar, adotar novas dinâmicas e modos de produção e suspender o funcionamento de espaços essenciais para o desenvolvimento e para a formação dos sujeitos como espaços escolares formais, centros de cultura, lazer e ambientes esportivos.

Toda essa movimentação é recente e está acontecendo aqui e agora. Enquanto essas letras são digitadas, os números de casos são atualizados, sistemas de saúde entram em colapso no mundo, os serviços funerários atuam aceleradamente, ruas, cidades e fronteiras são fechadas. Longe de entoar um discurso fúnebre, a razão de apresentar esse contexto, é sinalizar que tudo que se tem produzido intelectualmente no campo das ciências humanas e sociais sobre a pandemia da COVID-19 agora é preliminar, pois a disseminação mundial dessa doença e seus desdobramentos ainda estão em curso. Entretanto, ao mesmo tempo, é fundamental registrar e refletir sobre os desafios desse processo e das marcas que ele deixará no mundo.

A pandemia da COVID-19 ocasionou o fechamento de comércios e fronteiras, a instauração do home office em nível mundial e a suspensão das aulas nos espaços escolares, em função das medidas de distanciamento e isolamento social instituído por governos em todas as partes do mundo. Essas medidas, no entanto, são mais físicas do que sociais, em grande parte das nossas atividades diárias. Em todo mundo, as pessoas migraram suas interações para os ambientes online, forjando outras utilidades, apropriações e usabilidade. Ou seja, talvez as pessoas e sociedades nunca tenha estado tão próximas socialmente.

No campo da educação, os desafios que a área já enfrentava diante das transformações da sociedade contemporânea, ganharam novos contornos e as demandas impostas pela pandemia parecem ter instituído uma pedagogia do (im)previsível. Afinal, antes de ter tempo para entender e discutir as raízes da crise, como é comum no campo da educação, cobrou-se apresentação de respostas, soluções e

\footnotetext{
' Dados de 19 de maio de 2020 encontrados em https://www.paho.org/bra/covid 19

2 Dados de 19 de maio de 2020 https://pt.unesco.org/covid I9
} 
alternativas para que, por exemplo, todas as atividades acadêmicas não fossem abruptamente interrompidas. Teoricamente, precisava-se garantir o vínculo acadêmico.

No Brasil, governos estaduais e municipais decretaram a suspensão das aulas em todo território nacional. A suspensão das aulas nos espaços escolares físicos fez com que milhões de estudantes migrassem as interações pedagógicas para ambientes online, criando um grande fluxo em espaços e ferramentas até então utilizados prioritariamente pela Educação a Distância (EaD).

O discurso, especialmente dos gestores públicos e de instituições privadas de ensino, destaca o fato de que a suspensão está relacionada às atividades presenciais físicas, mas que ações remotas podem ser desenvolvidas, objetivando a manutenção de rotina pedagógica e aproveitamento das atividades à distância, quando do retorno das aulas regulares. Entretanto, o que se entende por presença na educação? Qual presencialidade tem sido solicitada no contexto de distanciamento provocado pela atual pandemia no âmbito pedagógico? Quais educações estão em curso durante a Pandemia COVID-19? As pessoas estão efetivamente distanciadas socialmente?

○ estudo realizado por meio de pesquisa bibliográfica e análise documental em fontes diversas, produzidas atualmente em razão da pandemia mundial, buscou responder a essas questões e discutir as noções de presencialidade e distanciamento social na interface com a educação, refletindo sobre os desafios apresentados frente à pandemia provocada pelo novo coronavírus e a pedagogia do (im)previsível instaurada nos sistemas de ensino. $\bigcirc$ argumento do artigo é de que enquanto áreas como entretenimento, comércio e comunicação rapidamente encontraram formas de garantir que a interação entre artistas e audiência, produtor e consumidor se adaptasse à nova realidade, fortalecendo a interação social e aproximando pessoas que se encontram prioritariamente em casa, as instituições de ensino ainda não apresentaram posicionamento articulado em relação ao papel da educação no atual contexto nem encontraram caminho para o desenvolvimento de ações pedagógicas efetivas com o momento que estamos vivendo, seja por resistência às práticas pedagógicas mediadas por Tecnologias Digitais da Informação e Comunicação (TDIC), seja pela ausência de políticas públicas para coordenar soluções pedagógicas em âmbito nacional. Essa distopia pode ter relação com a apropriação mais natural que os sujeitos fazem dos espaços online no campo do entretenimento, arte e comunicação, enquanto a escola convencional e tradicional ainda se apresenta obsoleta e incapaz de responder questões contemporâneas importantes, considerando que a transmissão de conteúdos é prioridade, ainda que esta amplie o distanciamento social. 


\section{O DISTANCIAMENTO É SOCIAL?}

A pandemia provocada pelo novo coronavírus trouxe ao nosso cotidiano informacional uma avalanche de dados sobre conceitos pouco conhecidos pela maior parte das pessoas no mundo: quarentena, isolamento social, distanciamento social, lockdown e mais uma série de termos relacionados à área de saúde que, de uma hora para outra, passaram a ser centro de toda produção intelectual, informacional e social em todos os continentes do globo. Esses termos, embora apresentados diariamente nos noticiários dos mais diversos veículos de comunicação, nos textos que circulam em aplicativos de mensagem e em lives ${ }^{3}$ nas plataformas digitais - que se têm multiplicado na mesma velocidade que o vírus causador da COVID- 19 - provocam falsas certezas e levantam dúvidas.

Compreender, discutir e problematizar esses conceitos são ações importantes para que seja possível fazer uma leitura do momento histórico que o mundo está vivendo. Essa não é a primeira pandemia que a humanidade enfrenta e, certamente, não será a última. Ao longo dos séculos, as civilizações tiveram de lidar com surtos, endemias, epidemias e pandemias geradas por diversos tipos de enfermidades que, muitas vezes, se assemelham tanto pelo modo de disseminação quanto de controle (UJVARI, 20I I).

As pandemias em geral têm nos cuidados com a higienização e a implantação do distanciamento e/ou isolamento social as medidas universais para conter a proliferação. Além da forma de contenção, mesmo considerando as diferenças temporais, biológicas, geográficas e sociais, as pandemias apresentam pontos de convergência como o caos social e nos sistemas de saúde; as mudanças de hábito e comportamento e a disseminação de informações equivocadas ou mesmo falsas e, por isso, é também pedagógico debatê-las.

\section{I As medidas de contenção no Brasil}

A Lei No. 13.979, de 6 de fevereiro de 2020, estabeleceu as medidas para "enfrentamento da emergência de saúde pública de importância internacional decorrente do coronavírus, responsável pelo surto de 2019" (BRASIL, 2020), autorizando que as autoridades adotassem medidas como isolamento, quarentena, determinação de realização compulsória de tratamentos médicos diversos e variados, restrição excepcional e temporária de saída e entrada no país e de circulação dentro do território brasileiro. Neste mesmo documento, se esclarece que:

Art. $2^{\circ}$ Para fins do disposto nesta Lei, considera-se: - isolamento: separação de pessoas doentes ou contaminadas, ou de bagagens, meios de transporte, mercadorias ou encomendas postais

${ }^{3}$ Expressão utilizada para designar transmissão ao vivo, em tempo real, em plataformas digitais. 
afetadas, de outros, de maneira a evitar a contaminação ou a propagação do coronavírus; e II quarentena: restrição de atividades ou separação de pessoas suspeitas de contaminação das pessoas que não estejam doentes, ou de bagagens, contêineres, animais, meios de transporte ou mercadorias suspeitos de contaminação, de maneira a evitar a possível contaminação ou a propagação do coronavírus (BRASIL, 2020a).

As medidas iniciais estabelecidas pelo governo brasileiro buscavam controlar a propagação do novo coronavírus no Brasil, considerando que ainda não havia sido diagnosticado nenhum caso no país. Desse modo, a orientação se restringia a isolar, separar ou restringir mobilidade de pessoas doentes ou possivelmente contaminadas. $\bigcirc$ primeiro caso no Brasil foi oficialmente notificado vinte dias depois na cidade de São Paulo ${ }^{4}$.

No entanto, pesquisa realizada pela Fiocruz indica que o SARS-CoV-2 começou a se propagar localmente nos países do ocidente muito antes da transmissão comunitária ser oficialmente reconhecida e medidas de controle serem implementadas. Segundo os pesquisadores, indivíduos infectados assintomáticos disseminaram o coronavírus antes da sua descoberta e constatação pelos sistemas públicos de saúde. Isso significa considerar que em janeiro o vírus já circulava no Brasil e a transmissão comunitária já era realidade no começo de fevereiro (DELATORRE et. al., 2020).

Segundo a Sociedade Brasileira de Infectologia (2020), transmissão comunitária é quando o número de casos de uma doença contagiosa se eleva exponencialmente, não podendo se identificar o agente transmissor. $\bigcirc$ Brasil declarou a confirmação de transmissão comunitária por meio da Portaria $N^{\circ}$. 454, de 20 de março de 2020b. Nesse mesmo período, de forma gradativa, os governos estaduais e municipais no país implantaram o distanciamento social amplo e, desse modo, em todo o território nacional, até o momento ${ }^{5}$, os espaços de lazer, esporte, entretenimento e cultura, além de instituições de ensino públicas e privadas de todos os níveis estão fechados para atividades presenciais físicas no intuito de evitar aglomerações.

Shows, espetáculos artísticos e aulas de cursos regulares da educação formal não estão acontecendo nos espaços convencionais. Porém, continuam acontecendo nas diversas plataformas digitais online, na tentativa de diminuir o distanciamento social e possibilitar que homens, mulheres e crianças não estejam completamente distantes e isolados. A partir dessa realidade que se espalhou pelo mundo em tempos de COVID-19, é que este estudo constrói a argumentação em torno desses termos tão repetidos atualmente: quarentena, isolamento social e distanciamento social.

De acordo com Nussbaumer-Streit et. al. (2020), a quarentena é uma das recomendações da Organização Mundial de Saúde (OMS) e uma estratégia importante na redução da ocorrência e mortalidade durante pandemias. Isso significa separar pessoas saudáveis de outras pessoas saudáveis que podem ter o vírus. Considerando que a literatura em saúde reconhece que muitos dos sujeitos são

\footnotetext{
${ }^{4}$ https://www.saude.gov.br/noticias/agencia-saude/46435-brasil-confirma-primeiro-caso-de-novo-coronavirus
}

${ }^{5}$ Maio de 2020 
assintomáticos e que a transmissão comunitária não consegue rastrear como se deu o contágio, todas as pessoas do mundo são suspeitas de estarem contaminadas pelo novo coronavírus e é por isso que o mundo adotou a quarentena como primeira ação de combate ao vírus. Assim, sua implementação associada a outras medidas de saúde pública e de controle (fechamento de escolas, restrições de viagens e distanciamento físico) são importantes para monitorar a disseminação da COVID-19. O isolamento também deve ser adotado quando as pessoas identificam sintomas de COVID-19, mesmo que o diagnóstico ainda não tenha sido confirmado. Já o distanciamento social é a recomendação geral durante a quarentena.

Basicamente, o distanciamento social objetiva a redução da interação física entre as pessoas de uma localidade com transmissão comunitária para diminuir a velocidade de transmissão do vírus e, desse modo, os sistemas de saúde ganham tempo para reforçar sua estrutura física e de recursos humanos. É, portanto, uma medida orientadora para que as pessoas assintomáticas ou oligossintomáticas - que não têm diagnóstico da doença e não estão em isolamento - mantenham-se distantes uma das outras.

distanciamento social pode ser ampliado (DSA) ou seletivo (DSS). No primeiro caso, há exigência de que todos os setores da sociedade permaneçam em casa durante a vigência do decreto de autoridade responsável, visando restringir ao máximo o contato entre as pessoas, fundamental para controlar o avanço acelerado da doença e consequente colapso no sistema de saúde, em razão de todas as situações que exigem, por exemplo, leitos hospitalares em Unidade de Terapia Intensiva. Já no segundo caso, apenas os grupos que possuem maior risco de desenvolver a doença ou que podem apresentar complicações mais graves são colocados em isolamento. No entanto, considerando que essas pessoas continuarão tendo contato com assintomáticos ou sintomáticas, o controle fica mais difícil (BRASIL, 2020c).

Por último, a estratégia mais severa é o chamado lockdown ou bloqueio total e deve ser adotado em situações que ameaçam gravemente os sistemas de saúde, pois, durante o lockdown todas as entradas e saídas das circunscrições isoladas são bloqueadas por profissionais de segurança e não há trânsito de pessoas ou veículos no perímetro bloqueado (BRASIL, 2020c).

Fechamento de espaços com circulação de muitas pessoas, como escolas, cancelamento de eventos artísticos e esportivos e o estímulo ao home office são ações de distanciamento social ampliado, objetivando evitar aglomerações. De acordo com a literatura especializada, no Brasil, se está - no âmbito coletivo - em quarentena com distanciamento social. Algumas pessoas, localidades e situações, no entanto, estão, estiveram ou estarão em lockdown ou isolamento em algum momento neste cenário pandêmico.

Todas essas medidas, de algum modo, provocam ou acentuam crises de naturezas diversas. Mascaro (2020) ressalta que não se deve reduzir a pandemia da COVID-19 aos aspectos conceituais, descritivos e explicativos no campo da natureza ou da biologia, tendo em vista que a pandemia instaura crises sociais e históricas. Para o autor (2020, p. 5) “(...) a reiterada fragilidade da relação humana com a 
natureza corresponde a uma parcela pequena dos problemas presentes. No fundamental, a dinâmica da crise evidenciada pela pandemia é do modelo de relação social (...)". O que cientistas sociais destacam (SANTOS, 2020; HARARI, 2020; MASCARO, 2020) é que as crises que emergem nos contextos pandêmicos são retratos de outras crises, especialmente as econômicas, originadas pelo modo de produção capitalista.

Assim, embora o argumento neste texto não se estruture a partir das discussões dos modos de produção econômicos, é importante destacar que a emergência da pandemia causada pela COVID-19 leva à superfície questões que a antecedem. A impressão que se tem é a de que o novo coronavírus se configura como uma chave que abriu a Caixa de Pandora ${ }^{6}$ do mundo contemporâneo e desvelou as suas fragilidades, limitações e fraquezas. Ao mesmo tempo, talvez tenha comprovado - enfim - a interligação global, ou seja, o reconhecimento de que todos os sistemas - saúde, economia, ambiente, educação, política, entretenimento e mais uma diversidade de áreas - estão interconectados de tal modo que uma crise das proporções de uma pandemia funciona como um efeito borboleta7 (CAPRA, 2012).

Desse modo, homens, mulheres e crianças são, simultaneamente, atores e plateia no drama vivido atual e mundialmente e, mais, todos potenciais vítimas. Esse contexto os coloca no lugar de quem precisa pensar sobre todas as transformações que estão ocorrendo numa velocidade imprecisa, pois não se consegue, com exatidão, identificar as variáveis de deslocamento e intervalo de tempo. No meio de tantas incertezas, conhece-se o suficiente do vírus para saber o tamanho do seu perigo e, no Brasil, conhecemse os contextos de outros povos que foram surpreendidos e afetados primeiramente por ele. Ou seja, ainda que com muitas incertezas e estudos em andamentos, há um Fio de Ariadne ${ }^{8}$ que indica as pistas de quais caminhos percorrer, sobretudo em áreas críticas e emergenciais como a saúde. Essa trilha indica que a medida mais eficaz para diminuir o contágio pelo novo coronavírus está em garantir o máximo de distanciamento social nas comunidades.

\subsection{Alegorias contemporâneas da pandemia}

Considerando já haver o entendimento de que a maior parte do mundo não está em isolamento social e lockdown, mas sim em quarentena associada ao distanciamento social, é que este texto se debruça especificamente sobre esse último conceito, já que, para Henrique (2020, p. 06), "talvez por simplificação pragmática ou por herdarmos a expressão já empregada em outros idiomas, temos utilizado a expressão

\footnotetext{
${ }^{6}$ Alegoria tirada do mito grego da criação de Pandora, a primeira mulher criada por Zeus. A caixa era um artefacto em forma de jarro que continha todos os males do mundo. Pandora, ao abrir a sua "caixa", deixa escapar todos os males exceto a esperança.

${ }^{7}$ Termo relacionado a Teoria do Caos que procura demonstrar que qualquer evento de pequena escala (como o bater de asas de uma borboleta) pode gerar consequências complexas imprevisíveis. (CAPRA, 20I2).

${ }^{8}$ Artefato criado por Ariadne, na mitologia grega, para ajudar Teseu a sair do labirinto construído por Dédalos.
} 
“isolamento social'". Contudo, Henrique (2020) acrescenta que a defesa da Organização Mundial de saúde e outros organismos e autoridades de saúde no mundo é a de que as pessoas se mantenham distantes fisicamente uma das outras, estabelecendo, inclusive distância mínima para quando for imprescindível sair de casa. Embora as distâncias mínimas eficientes ainda não estejam cientificamente comprovadas, dadas as inúmeras pesquisas que indicam distância mínima que variam de $1,5 \mathrm{~m}$ a $4 \mathrm{~m}$, é unanimidade que o vírus é menos contagioso se for respeitado o distanciamento físico.

O distanciamento físico foi estratégia para contenção da proliferação da gripe espanhola em 19 |8. A esse respeito, afirma Ujvari (2018, p. 42): “(...) fecharam escolas, clubes, fábricas, escritórios, conferências, reuniões, bares, teatros, cinemas e cancelaram jogos de futebol. Algumas cidades se esvaziaram pela fuga dos mais privilegiados". Pouco mais de cem anos depois, o mundo observa os mesmos movimentos, porém as janelas das casas do século passado que se abriam para eventualmente serem receptoras de informação e permitir alguma interação social entre as famílias que se confinavam, se amplificaram e ganharam outras perspectivas com a cibercultura.

As janelas online dos navegadores de internet, App e plataformas digitais de streaming e redes sociais são o mundo real, presencial, responsável por manter as pessoas conectadas e em interação. Esse contexto digital é produto da sociedade, resultado da insistência do homem em manter-se visível e em interação uns com os outros e é facilitado pela capacidade humana, relativamente recente, de se comunicar a grandes distâncias, com frequência, a milhares de quilômetros (SANTANA, 20 I 4).

A aldeia global de McLuhan (2006) é uma realidade, sendo a esfera pública do novo milênio. A sociedade contemporânea do novo milênio tem celebrado o social muito fortemente, a partir da quarta revolução tecnológica, quando as (TDIC) possibilitaram a concepção de estruturas computacionais que representam as conexões sociais na internet, em plataformas de redes sociais digitais. No entanto, o social não se refere unicamente a um conjunto de homens, mas a um conjunto de relações, as quais são conexões e trilhas por onde as mensagens transitam (SANTANA, 2014) e, neste sentido, a própria sociedade seria a rede social tão anunciada na atualidade.

Assim, a interação social, é um dos elementos de ação mais favorecido, ampliado e ressignificado com o advento da internet. A apropriação da internet por seus usuários cria linguagens e espaços e reconfigura percepções temporais e noções de presença e ausência. A internet se transforma, a partir das interações, apropriações, combinação de técnicas informáticas de linguagens, códigos e softwares e, de muitas maneiras, redimensiona modelos de convívio social e práticas de interação, estrutura ambientes virtuais - os quais funcionam como extensões das vivências experiências e trocas presenciais físicas - que têm como pressupostos fundantes a interação social mediada pelo computador e indica um contexto sócio-histórico diferente de tudo que a humanidade já vivenciou. 
Durante a pandemia da COVID-19, as interações sociais de toda natureza migram para o digital, seja para os App, sites ou plataformas digitais. Com o distanciamento físico impositivo, é o ciberespaço que acolhe as aglomerações humanas. A Associação Brasileira de Comércio Eletrônico ${ }^{9}$ identificou crescimento de $40 \%$ no mercado de produtos e serviços - mesmo com a ausência de oferta de alguns serviços como ingressos para espetáculos -; a plataforma Conviva ${ }^{10}$ indicou que os serviços de streaming tiveram aumento de 20\%; e as plataformas digitais e de redes sociais como Instagram e Youtube têm tido crescimento de acesso simultâneo por conta das lives promovidas por profissionais das mais diversas áreas, sobretudo, artistas da música que levaram seus shows para as plataformas alcançando públicos simultâneos de mais de três milhões de pessoas, ainda que inexistam políticas públicas de fomento à arte e à cultura no contexto do Brasil de 2020. Todos esses dados são apenas referentes aos primeiros noventa dias da pandemia no mundo.

Talvez as pessoas nunca tenham estado tão próximas e tão juntas, ainda que distantes. Rapidamente, diversos setores e profissionais se mobilizaram para tornar o distanciamento físico mais sociável possível. Personalidades e celebridades da política, literatura, teatro, música, esportes abriram suas janelas online para que o mundo pudesse não apenas compartilhar de suas intimidades, mas aprender junto um trabalho manual ou uma receita, dialogar sobre diversos temas e participar de inúmeras atividades artísticas e esportivas. As comemorações familiares mudaram para os aplicativos de comunicação por vídeo e os encontros de happy hour acontecem em janelas online. Parece que, a princípio, o mundo virou uma grande live ${ }^{11}$.

Assim, no panorama desenhado pela pandemia da COVID-19, onde o distanciamento físico entre as pessoas é uma orientação importante, ainda que muitos não possam adotá-la por necessidades mais imperativas de sobrevivência ou atuação nas atividades essenciais para o andamento da sociedade, o mundo está experimentando inúmeras intervenções e manifestações de disseminação social, de difusão social, de divulgação e interação social. De forma análoga a Henrique (2020), que requer a utilização do termo isolamento físico no lugar do isolamento social, esse estudo indica que o distanciamento que o mundo tem experienciado é da ordem do físico e, nunca, do social.

O distanciamento físico, por sua vez, tem emprestado novas demandas e oportunidades às interações sociais. Sem fazer análise qualitativa ou das motivações que mobilizam artistas, empresários e outros atores do entretenimento e ramos mais diversificados do comércio, a exemplo da alimentação e gastronomia, que - por força do perigo de aglomeração das suas atividades - precisaram reinventar suas atuações, apropriando-se do digital e online, garantindo a interação entre artistas e audiência, produtor e

\footnotetext{
${ }^{9}$ https://abcomm.org/Pesquisas/ecommerce-no-covid-konduto-abcomm.pdf Acessado em I4 de maio de 2020.

10 https://www.conviva.com/about/

" Live equivale, na dimensão do digital, "ao vivo". Na cibercultura, a expressão é utilizada para conceituar as transmissões ao vivo feitas por meio das plataformas de redes sociais digitais.
} 
consumidor, adaptando-se à nova realidade que, por sua vez, fortalece a interação social e aproxima pessoas que se encontram prioritariamente em casa, o mesmo parece não ter acontecido no mesmo ritmo, com a área da educação.

Ainda que a complexidade dos processos educativos seja considerada e não seja possível comparar linearmente com outros segmentos, é impossível não destacar o anacronismo da educação frente às transformações sociais. Quais redes de cooperação e de mobilização os sistemas de ensino têm apresentado nesse contexto de pandemia em que os mais diversos segmentos e instâncias têm se organizado para buscar se adaptar às transformações atuais? É imperativo já responder que as escolas ou redes de ensino que têm conduzido processos pedagógicos têm feito de forma mecânica, excludente e transmissionista, desconsiderando, por exemplo, todo o percurso científico teórico e metodológico, que a área de EaD já acumula, por exemplo.

Metaforicamente, é como se os mais diversos segmentos da sociedade estivessem em franca aceleração, enquanto as instituições de ensino (escolas e Universidade) correm atrás tentando alcançá-los sem sucesso. Esse anacronismo fica menos opaco quando se identifica a educação formal apenas ladeando as transformações sociais em curso, enquanto permanece presa em suas raízes do final do século XIX, quando começa a ser universalizada no Brasil, sendo extremamente conteudista (SANTANA E MOREIRA, 2020).

As instituições de ensino fecharam as portas à medida que a transmissão comunitária era confirmada nas diversas localidades do mundo, mas, sobretudo as instituições privadas de educação formal, migraram para os ambientes online com o objetivo de dar continuidade às atividades pedagógicas, evitar demissão em massa dos profissionais e interromper os contratos de serviço. Os anúncios das redes de ensino e instituições ${ }^{12}$ registravam a suspensão do ensino presencial e adoção de uma modalidade de ensino sem regulamentação e com pouco lastro teórico-metodológico: o ensino remoto. Porém, o que se entende por presença na educação? Qual presencialidade tem sido solicitada no contexto de distanciamento provocado pela atual pandemia no âmbito pedagógico? Quais educações estão em curso durante a Pandemia COVID-19?

\section{3 entre A PREsencialidade E O Distanciamento NA EDUCAÇÃO}

No Brasil, as aulas foram suspensas em todos os estados e no Distrito Federal à medida que a transmissão comunitária da COVID-19 era confirmada. Na prática, especialmente nas redes privadas de

12https://desafiosdaeducacao.grupoa.com.br/ead-alternativa-coronavirus/ e https://www.semesp.org.br/noticias/instituicoes-deensino-adotam-aulas-remotas-sincronas-durante-a-quarentena/ 
ensino, o mais importante era não paralisar as atividades ao ponto de que tantos vínculos profissionais e contratuais fossem rompidos em larga escala. Nas redes públicas de ensino, iniciativas foram criadas por parte das gestões pedagógicas centrais dos executivos municipais e estaduais da educação básica para que o ano letivo não fosse suspenso, considerando a possibilidade disposta na Lei de Diretrizes e Bases da Educação No. 9394/96 de que o ensino a distância pode ser adotado como complementação da aprendizagem no ensino médio, educação profissional técnica de nível médio, educação de jovens e adultos, educação especial ou, em situações emergenciais, na educação fundamental. $\bigcirc$ Decreto $N^{\circ}$ 9.057, de 2017 permite a realização de atividades a distância na educação básica, desde que franqueadas pelas autoridades educacionais estaduais e municipais.

A Medida Provisória No. 934, de 01 de abril de 2020 apresentou as normas de excepcionalidade sobre o ano letivo, na educação básica e superior, em razão da emergência de saúde pública que o país enfrenta, dispensando, os estabelecimentos de ensino da Educação Básica, "em caráter excepcional, da obrigatoriedade de observância ao mínimo de dias de efetivo trabalho escolar, desde que cumprida a carga horária mínima anual estabelecida nos referidos dispositivos, observadas as normas a serem editadas pelos respectivos sistemas de ensino" (BRASIL, 2020d).

Apenas em 04 de maio de 2020, o Conselho Pleno do Conselho Nacional de Educação (CNE) aprovou o Parecer N. 05/2020, "que dispõe sobre a reorganização do calendário escolar e sobre a possibilidade de cômputo de atividades pedagógicas não presenciais para fins de cumprimento da carga horária mínima anual, em razão da pandemia da Covid-19" (BRASIL, 2020e). Na prática, o Parecer do CNE reforça a possibilidade de adoção da modalidade EaD, conforme legislação vigente - a qual, no Brasil, está diretamente ligada ao uso das TDIC e à obrigatoriedade de encontros presenciais -; e destaca o Decreto-Lei No. I.044/1969 que pressupõe a "realização de atividades fora do ambiente escolar para estudantes que estejam impossibilitados de frequentar a unidade escolar por conta de risco de contaminação direta ou indireta, de acordo com a disponibilidade e normas estabelecidas pelos sistemas de educação" (BRASIL, 1969).

Embora no mesmo parecer o CNE reconheça as desigualdades estruturais do país, as fragilidades educacionais e diferenças no que diz respeito à alfabetização, os índices de acesso às escolas relacionando fatores socioeconômicos e étnico-raciais e as condições de acesso ao universo digital por parte dos estudantes, o documento do CNE/MEC autoriza, de maneira muito ampla, o desenvolvimento de atividades pedagógicas não presenciais, mediadas ou não por TDIC, para a educação básica, enquanto as restrições sanitárias e as medidas de distanciamento social continuarem vigentes no país e destaca que:

[...] a realização das atividades pedagógicas não presenciais não se caracteriza pela mera substituição das aulas presenciais e sim pelo uso de práticas pedagógicas mediadas ou não por tecnologias digitais de informação e comunicação que possibilitem o desenvolvimento de objetivos de aprendizagem e habilidades previstas na BNCC, currículos e propostas pedagógicas passíveis de serem alcançados através destas práticas (BRASIL, 2020e). 
Ainda que exista autorização legal para a continuidade das atividades pedagógicas nas instituições de ensino, por meio da modalidade a distância com mediação tecnológica, não existem orientações específicas e condições universais - ou o mais perto disso - para o desenvolvimento pedagógico efetivo e significativo por todas as redes de ensino. $O$ contexto é ainda mais complexo, quando se vive no Brasil uma crise precedente na educação, seja por seu percurso histórico de exclusão e favorecimento a determinados grupos quando da oferta da educação escolar regular, pelo seu anacronismo com o desenvolvimento da sociedade, no contexto da quarta revolução tecnológica (SCHWAB, 2019) ou pelos constantes processos de precarização sofridos por docentes e instituições públicas de ensino.

A pandemia da COVID-19, desse modo, acentua as situações de crise a que a população mundial já é submetida (SANTOS, 2020). No contexto da educação, esse argumento também é verdadeiro e, por isso, os riscos são grandes. $\bigcirc$ distanciamento físico colocou em outro extremo alternativas para lidar com a ausência de presencialidade imposta pelo novo coronavírus, mantendo o foco no aspecto que permanece prioritário na conjuntura educacional: a transmissão de conteúdos. Seja por mediação das TDIC ou por meio de consignas impressas, o que se tem adotado nas escolas de educação básica no país é a manutenção do tarefismo e transmissão de conteúdo sem significado, especialmente para os estudantes que ainda estão em processo de construção da autonomia pedagógica. Essa realidade, inclusive, parece desconsiderar o amplo campo de estudos, construção teórico-metodológica e legislação que regulamenta, define e dá suporte ao desenvolvimento daEaD desde a década de 90 (SALES, 20 I3).

O destaque do termo presença até aqui é proposital, haja vista o esforço realizado neste ensaio para problematizar conceitos que têm tido visibilidade e repetição - quase que automática - nas circunstâncias da pandemia vivenciada no mundo em 2020. No mesmo sentido que a percepção de distanciamento social foi desconstruída a partir do argumento que - em razão da atual conjuntura tecnológica mundial - as pessoas estão distantes fisicamente e não socialmente, o entendimento da presença e não-presença no campo da educação precisa ser questionado. Afinal, como é possível processos pedagógicos sem presença?

No dicionário, o verbete presença ${ }^{13}$ está relacionado a comparecimento, existência, participação e, no sentido figurado, à manifestação de personalidade forte ou ao fato de sentir alguém que não se consegue ver. Em todos eles, de alguma forma, o termo está ligado à materialidade física de uma coisa ou pessoa - ainda que de modo figurado. Presença, portanto, é o termo utilizado quando se quer dizer que algo está ou existe.

\footnotetext{
${ }^{13}$ pre.sen.ça - subst. fem: Fato de uma pessoa estar num lugar específico; comparecimento. Existência de uma coisa em um lugar determinado: presença de mosquitos. Fato de existir, de ter existência real num local; existência: a presença de índios na Amazônia. Participação em alguma coisa: sua presença trouxe glamour ao evento. [Figurado] Manifestação de uma personalidade forte capaz de chamar a atenção dos demais: sempre foi um sujeito sem presença. [Figurado] Algo ou alguém que não se consegue ver, mas que se sente por perto: sinto sua presença sempre comigo (houaiss.uol.com.br).
} 
No contexto da educação, convencionou-se associar a variação do termo - presencial - à modalidade de educação. E isso só acontece na LDB de 1996, aparentemente, para fazer uma contraposição ao que não é EaD. A educação presencial nunca foi tratada legalmente em nenhum dos documentos que estabeleceram as diretrizes da educação nacional até 1996. Embora também não esteja conceituada na seção das modalidades de ensino da LDB vigente e apareça como conceito apenas no Decreto No. 9.057/2017 que regulamenta o art. 80 da Lei n 9.394/96 para tratar da oferta de pósgraduação lato sensu, ela é a regra e não a exceção. Talvez por esse motivo nunca tenha sido definida conceitualmente nos dispositivos legais. Até porque, para isso, seria preciso dizer como desenvolver processos de educação, ainda que a distância, sem a presença.

Em regra geral, a literatura conceitua a educação presencial como o ensino tradicional convencional que se concretiza a partir da comunicação direta entre estudante e docente em um mesmo espaço nomeado sala de aula (ARETIO, 1994); como o processo educativo onde as tecnologias aplicadas se apoiam nos agentes professores, meios e alunos em sala de aula física (EL HAJJ, 2007); e como processos formais sistematizados que se desenvolvem a partir da presencialidade física em um mesmo espaço geográfico e por meio da orientação, controle ou mediação de um professor que é detentor de saberes e competências ainda não desenvolvidas pelos estudantes (SALES, 20 I3). Compreende-se, a partir dessa breve contextualização, que a definição da presencialidade na educação está diretamente relacionada à percepção de distância sentida pelos atores do processo, especialmente, o estudante.

Contudo, saindo do campo legal de definição e partindo para as construções epistemológicas e pedagógicas, é importante resgatar o entendimento de que, para Freire (200I , p. 35), toda circunstância e todo ato educativo implicam presença e, nesta perspectiva, o autor argumenta que mais do que programas, tecnologias, projetos, métodos e currículos é primordial uma conexão entre o " sujeito que ensinando, aprende e o sujeito que, aprendendo, ensina". A presença arquiteta os objetos do conhecimento, a práxis educativa e processos significativos de aprendizagem e, portanto, nunca deveria ser um conceito, condição ou fundamento dispensável nos processos pedagógicos, pois para Síveres (20 I5, p. 80), "a presença se caracteriza como um exercício constante da condição humana, um percurso contínuo de construção das ciências e, como tal, impacta um projeto de ensino e aprendizagem".

A presença, partindo deste pressuposto, é elemento fundamental da condição humana e se anuncia de formas diversas, mas, para Síveres (20I5), pode ser compreendida sob o alicerce da dimensão dialogal e se apresenta, particularmente, nas experiências sociais, em que os sujeitos, grupos e comunidades se constituem enquanto estiverem presentes. No século $X X \mathrm{I}$, a presença se configura de muitas formas, pois estas experiências sociais são mediadas por tecnologias e suportes diversos, desde a oralidade face a face sem nenhuma interface de telecomunicação até a linguagem digital que estrutura plataformas de comunicação online. 
Assim, seja na EaD, no Ensino Remoto e mesmo em qualquer modalidade educativa ou método de ensino, a presença não pode ser facultativa. Da mesma forma, na perspectiva da pedagogia da presença, segundo Síveres (20 I 5, pp. 88-89), todo saber é um presente que encontra sua origem na presença que:

[...] contribui para que a construção dos conhecimentos, vivenciados no espaço educacional, não se transformem numa mercadoria a ser adquirida, mas num presente a ser desvelado. Os saberes são, portanto, mais do que produtos comerciáveis; são presentes que seriam saboreados; por isso os saberes são sabores e os sabores são saberes. Neste caso, o presente (...) se dá quando existe presença e encontro, que não precisa, necessariamente, ser físico e biológico. O presente acontece de modo especial, quando existe um significado na relação e quando essa relação tem como parâmetro a gratuidade. Essas categorias, que se revelam nas relações pessoais e sociais, são, também, indicadores para projetos educacionais.

Assim, em consonância com Sales (2013, p. I19), "se há ação humana, cognitiva, social, material, afetiva, há presença, e se há presença a distância não está determinada" e, portanto, a distância não é decisória, pois ela se manifesta independente da presença física tanto a partir da escolha do sujeito em ausentar-se ou não interagir, quanto pela natureza dos encaminhamentos pedagógicos que, muitas vezes, ainda que fisicamente no mesmo espaço geográfico, promovem distanciamento pedagógico e social. Ainda segundo Sales (idem),

(...) presencialidade física é uma perspectiva restrita à medida que concebemos a interação humana a partir do potencial de mediação telemática, reconhecendo que o sujeito está presente a cada momento em que age/interage/constrói/destrói através da sua participação nos processos desenvolvidos nos espaços em que o virtual, potencial e atual se alternam continuamente.

O distanciamento físico - indispensável em razão do novo coronavírus - não deveria promover uma celebração à não presencialidade na educação como alternativa para garantia da continuidade dos processos pedagógicos formais, pois o que tem sido identificado - seja pela experiência, pelo acompanhamento dos relatos de profissionais e familiares ou pelas manifestações na esfera pública que é a internet - são processos formais de ensino tradicionais presenciais - mas, pedagogicamente sem presença - sendo migrados para o ensino remoto com a equivocada tentativa de enquadrar esses processos como Educação a Distância de maneira improvisada, reforçando que enquanto o distanciamento físico é cada vez mais social, a educação é cada vez menos presencial.

\section{I Por uma pedagogia da presença no contexto da pedagogia do (im)previsível}

Efetivamente, como demarca Nóvoa (2020), a comunidade educacional não sabe como lidar com a crise provocada pela pandemia da COVID-19 e, neste caso, a primeira coisa a ser feita é reconhecer com humildade o não saber. O professor destaca ainda que esse não saber é parte de um paradoxo, pois, ao mesmo tempo que o reconhece, entende que é fundamental agir em defesa da educação como bem 
público e bem comum, por uma educação capaz de lutar contra as desigualdades sociais e isso significa manter a continuidade pedagógica mesmo no contexto de crise.

Ainda que reconhecendo a heterogeneidade e complexidade das circunstâncias educativas no mundo, especialmente no Brasil que, por exemplo, tem um Ministério da Educação que se abstém de propor estratégias para a crise da área da educação frente à pandemia, Nóvoa (2020) marca de maneira convicta que interromper as atividades pedagógicas - sobretudo na educação pública - não pode ser uma solução, sob o risco de que uma vez interrompido o vínculo pedagógico, o estudante pode não retornar ao espaço escolar. Ou seja, é preciso reação imediata para a garantia da continuidade pedagógica. A defesa da presença física para a efetividade do processo educativo precisa ser, portanto, sublimada. Quais são essas educações que têm dado conta da continuidade pedagógica?

Nesse sentido, as soluções alternativas para o enfrentamento da quarentena escolar, são representadas por possibilidades relacionadas à Educação a Distância mediada por diversas tecnologias: desde a educação online, possibilitada pelas plataformas digitais e seus múltiplos recursos interativos e de audiovisual - como é o caso do Governo Estadual de Santa Catarina e o planejamento de aulas online via Google Classroom ${ }^{14}$; passando pela educação via satélite, transmitida não apenas pela internet, mas pela TV aberta, como está acontecendo no estado do Amazonas com o projeto Aula em Casa ${ }^{15}$; até a alternativa de disponibilizar material didático impresso para os estudantes, como têm feito a Secretaria Municipal de Educação de Salvador ${ }^{16}$ que divulgou em abril de 2020 nota com anúncio de impressão e distribuição de atividades semanais para os estudantes do Ensino Fundamental I e EJA realizarem em casa enquanto durar o que a Secretaria de Educação chama de isolamento social.

\begin{abstract}
Semanalmente, será divulgado no portal da Smed um conjunto com cinco atividades, abrangendo as disciplinas Língua Portuguesa, História, Geografia e Ciência. Todas as escolas terão acesso e farão a impressão e entrega desses exercícios, juntamente com um lápis e borracha para as famílias dos alunos. Após resolução das questões pelos alunos, a partir da pesquisa nos livros da rede que já foram distribuídos ou em meio digital, os familiares deverão entregar as atividades na escola e pegar um novo material (SMED, 2020).
\end{abstract}

Juntamente com a informação de que atividades - que não foram ao menos produzidas pelos docentes - seriam entregues às famílias dos estudantes matriculados em cada escola, os docentes da Rede Municipal de Salvador receberam orientação de que as atividades respondidas e devolvidas estariam disponíveis para que fossem retiradas nas unidades de ensino, efetuadas a correção e alimentado o sistema acadêmico.

O exemplo pontual da Secretaria Municipal de Educação de Salvador reforça o fato de que, surpreendidos pelo contexto da pandemia, da quarentena e da imposição do distanciamento físico, nas

\footnotetext{
${ }^{14}$ https://www.sc.gov.br/noticias/temas/coronavirus/coronavirus-em-sc-governo-do-estado-estabelece-sistema-de-trabalhopara-atividades-escolares-nao-presenciais 
condições do distanciamento social ampliado, as escolas não sabem como lidar com a situação pedagógica a partir dessa realidade. Particularmente pelo fato de a presença física se configurar condição estruturante para a educação formal.

Entre o previsível e o imprevisível na crise que a educação vivencia em razão da pandemia, é importante destacar que essa prática de envio de atividade impressa, do modo que está sendo desenvolvido, sequer pode ser considerada ensino remoto e, menos ainda, EaD. Mesmo assim, o argumento para práticas como essas é a impossibilidade da presença. A situação exemplificada em tela se repete, em diferentes formatos, por cidades e estados brasileiros. Foco na ausência da presencialidade física de estudantes e professores, transpondo didaticamente para ações à distância mediadas por tecnologias digitais ou não digitais, porém, desconsiderando todas as habilidades, competências, formação e planejamento necessários para o desenvolvimento da modalidade à distância sem a presença física material, mas com a presença que os processos educativos exigem.

A garantia de continuidade pedagógica, mediada por tecnologia digital ou não, nos moldes como vem sendo feito, em um país tão desigual como o Brasil, no mínimo, reforça a exclusão. Santos (2020) destaca, inclusive, que qualquer quarentena é sempre segregadora, tendo em vista que é mais difícil para alguns grupos do que para outros. Em um país como o Brasil, onde há uma ampla oferta de EaD por parte das universidades públicas e privadas, um vasto campo de pesquisa, experimentação e iniciativas que reconhecem o Ensino Híbrido e a Educação Online como possibilidades efetivamente pedagógicas de construção e difusão do conhecimento e que, portanto, possui pesquisadores, formadores, docentes com bagagem teórica e metodológica para pensar em soluções pedagógicas que minimizem a necessidade da presença física, é curioso que não se consiga estruturar políticas públicas de ações formativas que permitam à comunidade escolar do país sentir-se minimamente segura em relação aos mecanismos adotados para viabilizar situações de ensino-aprendizagem.

É importante que escolas e educadores se apropriem da esfera pública que é a internet, especialmente neste contexto de incertezas, mas de demandas de aprendizagem. Nóvoa (2020) destaca que os instrumentos e contextos adotados pela educação, em razão da pandemia são exceções e não a nova normalidade. As ações que vêm sendo adotadas seriam importantes para manter o compromisso, comunicação e a capacidade de estar junto. Contudo, as práticas que vêm sendo adotadas são aligeiradas, improvisadas e sem definição do sentido para o qual estão sendo aplicadas.

portal de notícias $\mathrm{GI}^{17}$, ouviu familiares e professores de localidades cuja continuidade pedagógica foi uma escolha de governos municipais e estaduais. A sensação é a mesma que se tem ao ler as conversas com pessoas próximas ou mesmo quando se identifica a própria realidade: 2020 é um ano 
que parece estar perdido pedagogicamente. Além dos improvisos que deixam claro não apenas a falta de habilidade para conduzir processos pedagógicos sem a presença física, mas também a exclusão digital do país, existe o fato de que todas as pessoas das comunidades escolares estão enfrentando impactos diversos do contexto pandêmico. A conjuntura atual influencia diretamente o cotidiano e, neste momento, a preocupação com continuidade de transmissão de conteúdo curricular deveria ser o menos importante. Diz Portilho (2020, on line):

[...] eu não me preocuparia com o conteúdo. Peço que conversem sobre esse momento histórico com as crianças, mostrem o que é o ser humano, a questão da solidariedade, do respeito, o que é ficar em isolamento, o que é o vírus, a higiene. Tudo é conteúdo.

O fundamental, nesse contexto, é possibilitar vínculo afetivo e de segurança. Promover interação social para que as pessoas se sintam próximas, mesmo que distantes fisicamente. Desse modo, a vivência de agora é um momento oportuno para aprender, especialmente sobre temas que, normalmente ficam distante da escola e, efetivamente, levar para a educação formal regular princípios essenciais para a educação do século XXI como autoria, engajamento, autonomia, coletividade, cooperação e criatividade. Esses princípios são importantes para que as comunidades escolares se preparem para a nova normalidade que não se sabe quando chegará, mas que, certamente, irá acelerar a história e as marcas vivenciadas durante a Pandemia da COVID-19 e refletirão significativamente na sociedade que será reconstruída.

Segundo dados da UNESCO (2020), 90\% das escolas no mundo suspenderam as atividades durante os períodos mais críticos da quarentena, o que significa mais de I bilhão de estudantes vivenciando essas novas educações que podem ser desenvolvidas de maneira improvisada e desarticulada com as demandas atuais para atender as exigências do século XXI. É necessário, a partir desse momento transitório de crise, em que questões muito importantes do campo da educação estão sendo evidenciadas, construir a mobilização que promoverá as transformações que já eram imprescindíveis antes da crise causada pela pandemia da COVID-19 como: reconhecer outros modos e modelos de aprendizagem, a partir dos referenciais teóricos e metodológicos que descrevem e situam os processos pedagógicos mediados por tecnologia digital, ampliando e atualizando práticas pedagógicas que podem ter na Educação Online (SANTOS, 2019) inspiração para sua efetividade: criar novos espaços de aprendizagem, bem como o acolhimento de outros espaços educativos, como os que surgem e se estruturam nas plataformas e redes sociais digitais; pensar em outras organizações de tempos pedagógicos, considerando que a presença física não é condição exclusiva de aprendizagem e estimular a reinvenção do trabalho docente.

Essas transformações não desconsideram a importância da interação e aproximação física dos atores no processo educativo, muito menos do espaço escolar como ambiente de encontros e narrativas pedagógicas. Entretanto, a pandemia expõe a necessidade urgente de redefinição e ressignificação para que professores e alunos construam fortemente a noção de pertencimento por meio da presença 
construída entre a proximidade e o distanciamento. Para Costa (200I), pela proximidade, o docente se aproxima ao máximo do estudante, buscando identificar-se de forma empática e significativa, construindo uma relação pedagógica de qualidade; o distanciamento é necessário para o docente se afastar criticamente para compreender o modo como suas ações de relacionam na articulação da ação educativa.

Essa presença não se encerra na particularidade dos que estão fisicamente presentes, mas se expande com outras presenças do processo pedagógico e, desta maneira, mais possibilidades educativas poderão ser criadas, organizadas e sistematizadas (SÍVERIS, 20I5). Na perspectiva da pedagogia da presença, é necessário despertar o estudante para que se interesse pelo fato de aprender e demonstre desejo por aquilo que aprende; é fundamental conscientizar o professor de que é preciso gostar de ensinar e, não menos importante, assegurar que princípios educativos de autonomia e liberdade sejam construídos e façam parte da sociedade. A pandemia da COVID-19, e o seu forçoso e imperativo distanciamento físico, é uma oportunidade de, finalmente, a educação aceitar que a transição digital (NÓVOA, 2020) é uma condição indispensável e não uma escolha.

\section{CONSIDERAÇÕES FINAIS}

O cenário pandêmico concede uma permissão desordenada à realidade e, desse modo, todo esforço de analisá-lo é falho justamente porque a vida cotidiana do agora está sempre na vanguarda do que se sente ou se percebe sobre ela (SANTOS, 2020). Escrever sobre isso, portanto, é como estar diante de um precipício do qual não se conhece a profundidade. São perspectivas provisórias e iniciais. Ainda assim, discutir sobre esse panorama é um modo de registrar as reflexões e incertezas vivenciadas neste momento, não com o intuito de apresentar conclusões, mas problematizações que ajudam a compreender o período histórico marcado pela Pandemia da COVID- 19.

Talvez a certeza mais uníssona é a de que a pandemia e a quarentena que o mundo vem vivenciando em tempos e velocidades diferentes, expõem as fragilidades sociais e educativas da humanidade, ao tempo em que descortinam possíveis alternativas de adaptação e transformação aos modos de viver, produzir, consumir, conviver e aprender nas décadas iniciais do século $X X \mid$. A educação em tempos de cibercultura precisa resgatar a compreensão freireana de que a prática pedagógica não pode ser mera transferência de conhecimento, mas deve permitir a construção de contextos para a sua própria produção ou construção.

Da mesma forma que Santos (2020) ressalta o fato da pandemia causada pelo novo coronavírus ser uma demonstração do encerramento de um ciclo de sociedade que começou a se estabelecer no século XVII, este texto considera que o ciclo educativo iniciado no século XVII, com a universalização da 
educação laica e pública e a influência da Revolução Francesa e a Revolução Industrial, há muito vem dando indícios de que precisa se renovar.

É grande e necessário o desafio de reconhecer as potencialidades que despontam com, na e para as redes sociotécnicas, de maneira a potencializar a inteligência coletiva. A educação é via fundamental e imprescindível para que a potência se torne realidade, de modo a reconhecer e aceitar as demandas pedagógicas, o potencial da conectividade e da mobilidade digital e sua implicação para a educação do século $X X I$. A crise instaurada pelo surgimento do novo coronavírus é uma oportunidade singular de reconhecer esses desafios, identificar os possíveis limites e assumir as potencialidades de transformação de uma educação inspirada pela pedagogia da presença e articulada com princípios e fundamentos da cibercultura.

\section{REFERÊNCIAS}

ARETIO, L. G. La educación a distancia: de la teoria a la prática. Barcelona: Ariel, 1994.

BRASIL. Lei No 13.979, de 6 de fevereiro de 2020. Dispõe sobre as medidas para enfrentamento da emergência de saúde pública de importância internacional decorrente do coronavírus responsável pelo surto de 2019. Diário Oficial da União, Brasília,07 fev. 2020a.

BRASIL. Portaria No. 454, de 20 de março de 2020. Declara, em todo o território nacional, o estado de transmissão comunitária do coronavírus (covid- 19). Diário Oficial da União, Brasília, 20 mar.2020b.

BRASIL. Boletim Epidemiológico: Especial Doença pelo Coronavírus 20 19. Ministério da Saúde, 06 abr. 2020c.Disponível em: https://portalarquivos.saude.gov.br/images/pdf/2020/April/06/2020-04-06---BE7--Boletim-Especial-do-COE---Atualizacao-da-Avaliacao-de-Risco.pdf. Acesso em: 10. mai. 2020.

BRASIL. Medida Provisória No. 934, de 0 I de abril de 2020. Estabelece normas excepcionais sobre o ano letivo da educação básica e do ensino superior decorrentes das medidas para enfrentamento da situação de emergência de saúde pública. Diário Oficial da União, Brasília, 0 I abr. 2020d.

BRASIL. PARECER CNE/CP No 5/2020. Reorganização do Calendário Escolar e da possibilidade de cômputo de atividades não presenciais para fins de cumprimento da carga horária mínima anual, em razão da Pandemia da COVID- 19. Diário Oficial da União, Brasília, 04 mai. 2020e.

BRASIL. DECRETO No 9.057, de 25 de maio de 20 17. Regulamenta o art.80 da Lei n 9.394, de 20 de dezembro de 1996, que estabelece as diretrizes e bases da educação nacional. Diário Oficial da União, Brasília, 25 mai. 2017.

BRASIL. Lei No. 9.394, de 20 de dezembro de 1996. Estabelece as diretrizes e bases da educação nacional. Diário Oficial da União, Brasília, 20 dez. 1996.

BRASIL. Decreto-Lei No. I.044, de 21 de outubro de 1969. Dispõe sôbre tratamento excepcional para os alunos portadores das afecções. Diário Oficial da União, Brasília, 21 out. 1969.

CAPRA, Fritjjof. A teia da vida: uma compreensão científica dos sistemas. São Paulo: Cultrix, 2012. 
COSTA, Antonio C. G. Por uma pedagogia da presença. São Paulo: Global, 2001 .

DELATORRE, E. MIR, D. GRÄF, T. BELLO, G. Tracking theonset date ofthecommunity spread of SARSCoV-2. In: Western Countries [Submitted]. Mem Inst Oswaldo Cruz E-pub: 24 Apr 2020. Disponível em: https://memorias.ioc.fiocruz.br/article/I0702/0 183 -tracking-the-onset-date-of-the-communityspread-of-sars-cov-2-in-western-countries. Acesso em: 20 mai. 2020.

EL HAJJ, Zaina Said. Educação Presencial e Não Presencial no Brasil. In: Congrèsconjoint InstitutInternationaldesCoûts (IIC) - ISEOR, 2007, Lyon. I Congrès Transatlantique de Comptabilité, Audit, Contróle de gestion, Gestiondescoúts et Mondialisation. Lyon: Institut de SocioEconomiedesEntreprises et desOrganisations, 2007. v. i. p. I - 15.

FREIRE, Paulo. Política e educação. São Paulo: Cortez, 2001 .

PORTILHO, Evelise. In: GI. Educação. Disponível em:

https://gl .globo.com/pr/parana/educacao/noticia/2020/05/21/professora-relata-preocupacao-com-ascriancas-em-meio-a-pandemia-foi-tirado-de-repente-a-infancia-a-escola-a-liberdade.ghtml. Acesso em: 21 mai. 2020.

HARARI, Y. N. Na batalha contra o Coronavírus, faltam líderes à humanidade. São Paulo: Companhia das Letras, 2020.

HENRIQUE, T. Covid- 19 e a Internet (ou Estou em isolamento social físico). Revista Interfaces Científicas - Humanas e Sociais, v. 8, n. 3, 2020. Disponível em: https://periodicos.set.edu.br/index.php/humanas/article/view/87/3. Acesso em: 10 mai. 2020.

MASCARO, Alysson Leandro. Crise e pandemia. São Paulo: Boitempo, 2020.

MCLUHAN, Marshall. Os meios de comunicação como extensões do homem. São Paulo: Cultrix, 2006.

NÓVOA, António. Palestra proferida na abertura da Formação Continuada Territorial a Distância, Salvador (Bahia), abr. 2020. Disponível em: https://www.youtube.com/watch?v=wx-deAxdegE. Acesso em 30 abr. 2020.

NUSSBAUMER-STREIT, Barbara. MAYR, Verena. DOBRESCU, Andreea L. CHAPMAN, Andrea. PERSAD, Emma. KLERINGS, Irma. WAGNER, GERNOT. SIEBERT, Uwe. CHRISTOF, Claudia. ZACHARIAH, Casey. GARTLEHNER, Gerald. Quarantine alone or in combination with other public health measures to control COVID- 19: a rapid review. In: Cochrane Systematic Review. 08 Apr.2020. Disponível em:

https://www.cochranelibrary.com/cdsr/doi/I0. I002/I465 I858.CD0 I3574/full\#CD0 I 3574-abs-000 I. Acesso em: 20 mai. 2020.

SALES, KathiaMarise Borges. Cognição em ambientes com mediação telemática - uma proposta metodológica para análise cognitiva e da difusão social do conhecimento. 20 I3. 24 If. Tese (Doutorado em Difusão do Conhecimento). Faculdade de Educação, Universidade Federal da Bahia, Salvador, 20 I3.

SANTANA, Camila. Visibilidade mediada: estratégias e ações docentes no Twitter. 20।4. 257f. Tese (Doutorado em Educação). Faculdade de Educação, Universidade Federal da Bahia, Salvador, 2014.

SANTANA, Camila. MOREIRA, Antônio. Cartografando experiências de aprendizagem em plataformas digitais: perspectivas emergentes no contexto das Pedagogias das Conexões. In: LUCENA, Simone.

Espaços de aprendizagem em redes colaborativas na era da mobilidade. No prelo 2020. 
SANTOS, Boaventura de Sousa. A cruel pedagogia do vírus. São Paulo: Boitempo, 2020.

SANTOS; Edméa. Pesquisa-formação na cibercultura. Teresina:EDUFPI, 2019.

SCHWAB, K. A Quarta Revolução Industrial. São Paulo: Edipro, 2019.

SÍVERES, Luiz. Encontros e diálogos: pedagogia da presença, proximidade e partida. Brasília: Liber Livro, 2015.

SMED. Alunos da rede municipal têm atividades pedagógicas em casa a partir de segunda. Disponível em: http://educacao.salvador.ba.gov.br/alunos-da-rede-municipal-tem-atividades-pedagogicas-em-casaa-partir-de-segunda-27/. Acesso em: 18 mai.2020.

SOCIEDADE BRASILEIRA DE INFECTOLOGIA. Informe da Sociedade Brasileira de Infectologia (SBI) sobre o novo coronavírus. São Paulo, 2020. Disponível em: www.infectologia.org.br > admin > zcloud > 2020/03. Acesso em: 15 mai. 2020.

UJVARI, Stefan Cunha. Pandemias: A humanidade em risco. São Paulo: Contexto,20I I.

UNESCO. Suspensão das aulas e resposta à COVID-19. Disponível em:

https://pt.unesco.org/covidl9/educationresponse. Acesso em: 19 mai. 2020.

\section{COMO CITAR ESSE ARTIGO}

SANTANA, Camila. Pedagogia do (im)previsível: pandemia, distanciamento e presencialidade na educação. Debates em Educação, Maceió, v. I2, n. 28, p. 42-62, Set./Dez. 2020. ISSN 2175-6600.

Disponivel em: https://www.seer.ufal.br/index.php/debateseducacao/article/view/I0308. Acesso em: dd $\mathrm{mmm}$. aaaa. 